УДК 616.345

\title{
КРИТЕРИИ МОРФОЛОГИЧЕСКОЙ ДИАГНОСТИКИ НЕСПЕЦИФИЧЕСКОГО ЯЗВЕННОГО КОЛИТА
}

\author{
Нерсесян Кристина Сейрановна \\ Арефина Вероника Олеговна \\ Абасова Жала Азад Кызы \\ студенты
}

Научный руководитель: Молокова Ольга Александровна

д.м.н., доцент, профессор кафедры патологической анатомии и судебной медицины

ФГБОУ ВО «Тюменский государственный медицинский университет»

Министерства здравоохранения Российской Федерации

\begin{abstract}
Аннотация: Данная статья посвящена изучению проблемы морфологической дифференциальной диагностики неспецифического язвенного колита с другими воспалительными заболеваниями кишечника, в частности с болезнью Крона. Продемонстрирована и описана их макро- и микроскопическая картина, иллюстрирующая гистологические отличия между патологическими процессами по материалам биопсии и операционному материалу, взятым при выполнении оперативных вмешательств.
\end{abstract}

Ключевые слова: неспецифический язвенный колит, болезнь Крона, инфекционный колит, амебный колит, морфологическая диагностика

\section{CRITERIA FOR MORPHOLOGICAL DIAGNOSTICS OF NON-SPECIFIC ULCERATIVE COLITIS}

\author{
Nersesyan Kristina Seyranovna \\ Arefina Veronika Olegovna \\ Abasova Jala Azad Kyzy \\ Molokova Olga Alexandrovna
}

\begin{abstract}
This article is devoted to the study of the problem of morphological differential diagnosis of ulcerative colitis with other inflammatory bowel diseases, in particular with Crohn's disease. Their macro- and microscopic
\end{abstract}


picture is demonstrated and described, illustrating histological differences between pathological processes based on biopsy materials and samples taken during surgical interventions.

Key words: non-specific ulcerative colitis, Crohn's disease, infectious colitis, amoebic colitis, morphological diagnostics

Актуальность. В последние годы наблюдается неуклонный рост интереса врачей к проблеме хирургического лечения неспецифического язвенного колита, что объясняется увеличением заболеваемости и распространенности этой болезни во всем мире и, особенно, в индустриально развитых странах, с развитием тяжелых осложнений, в том числе рака толстой кишки. Язвенный колит - это диффузное рецидивирующее хроническое не трансмуральное иммуноопосредованное воспалительное заболевание [1, с.1641], которое ограничивается толстой кишкой и характеризуется язвенно-деструктивными дефектами ее стенки, преимущественно затрагивающее слизистую оболочку. Развитие болезни связано с воздействием факторов риска окружающей среды, приводящих к неадекватным иммунным ответам у генетически восприимчивых людей [2, с.643]. В зависимости от анатомической степени поражения пациентов можно классифицировать как больных проктитом, левосторонним колитом (вовлекающим сигмовидную кишку с поражением нисходящей кишки или без) или панколитом. У некоторых также развивается воспаление подвздошной кишки (обратный илеит), что иногда затрудняет дифференциацию от болезни Крона. У пациентов обычно наблюдается кровавый понос (часто ночной и послеобеденный), отхождение гноя, слизи или того и другого, а также спазмы в животе во время акта дефекации. Несмотря на сходную клиническую симптоматику с другими воспалительными заболеваниями кишечника, неспецифический язвенный колит характеризуется ключевыми особенностями в патогенезе и характере поражения желудочно-кишечного тракта как на макроскопическом, так и на микроскопическом уровне. С этиологической точки зрения как неспецифический язвенный колит, так и болезнь Крона имеют много общего между собой, но имеются существенные морфологические особенности. Частота язвенного колита почти в два раза выше, чем болезни Крона. Всё это привлекает пристальное внимание к данному вопросу и специалистов, и всех тех, кто интересуется проблемами современной медицины [3, с.220]. 
Цель исследования. Выявить морфологические изменения, характерные для неспецифического язвенного колита, по материалам биопсийного и операционного исследования, привести критерии дифференциальной диагностики с другими заболеваниями кишечника.

Материал и методы исследования. В ГБУЗ ТО «Областное патологоанатомическое бюро» МКМЦ «Медицинский город» изучены биопсии кишечника и операционный материал. Морфологический материал был получен у пациентов, которым в МСЧ «Нефтяник» г. Тюмени было выполнено биопсионное исследование, а также оперативное лечение по поводу неспецифического язвенного колита с тотальным поражением всех отделов толстого кишечника с тяжелым клиническим течением. Произведено макроскопическое исследование материала и микроскопическое изучение стеклопрепаратов, окрашенных стандартными гистологическими методиками. Выполнен статистический анализ с распределением по полу и возрасту.

Результаты исследования. Статистический анализ показал, что соотношение пациентов мужского и женского пола составило $1: 1$. Из них 62\% - работающие, 16\% - учащиеся и пенсионеры, остальные - 22\%. Кривая распределения пациентов по возрастной категории выявила, что пик заболеваемости отмечается в возрасте от 28 до 40 лет у представителей обоих полов [3, с. 221].

Произведено патоморфологическое исследование 681 биопсии прямой кишки и 14 случаев операционного материала - удаленных пораженных участков прямой кишки. В операционном материале острая форма неспецифического язвенного колита представлена в 4 случаях. Она характеризуется утолщенными, отёчными, полнокровными складками слизистой оболочки, покрытыми полупрозрачной слизью. Выявляются многочисленные язвы, эрозивные изменения. При микроскопическом исследовании определяется диффузное утолщение мышечной пластинки слизистой оболочки, инфильтрация собственной пластинки слизистой лимфоцитами, нейтрофильными лейкоцитами и плазмоцитами, формирование крипт - абсцессов с изъязвлениями, фибриноидный некроз стенок сосудов (рис. 1, 2). 


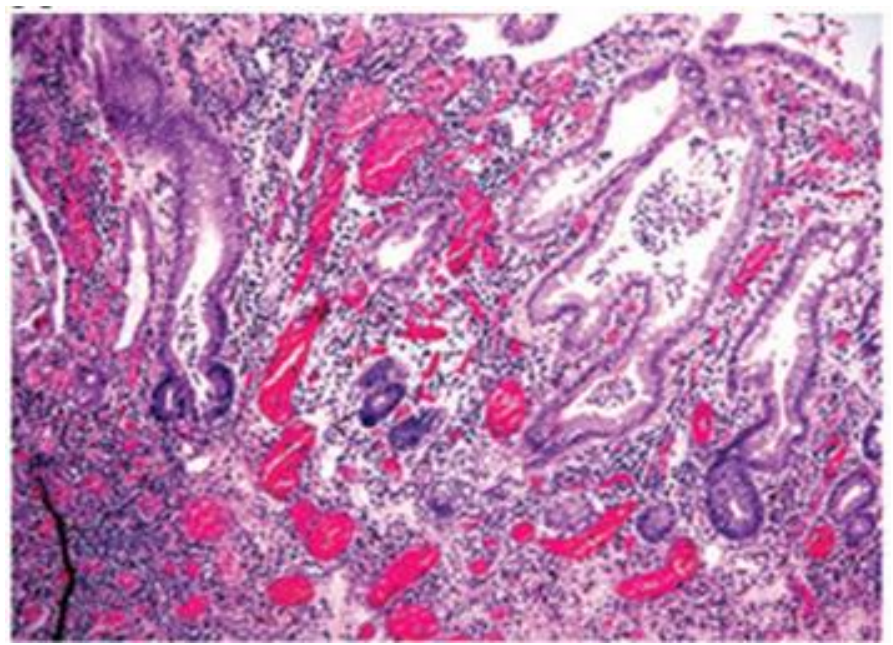

Рис. 1. Острый неспецифический язвенный колит. Воспалительная инфильтрация слизистой оболочки, полнокровие сосудов.

Окраска гематоксилином и эозином. Ув.X100

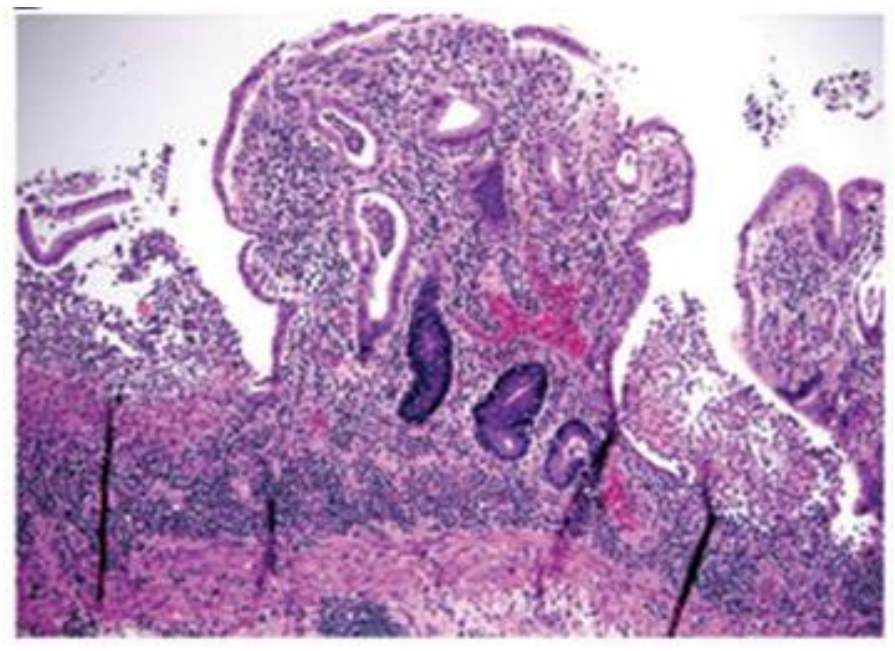

Рис. 2. Острый неспецифический язвенный колит. Укорочение железистых крипт слизистой оболочки. Окраска гематоксилином и эозином. Ув.X100

В 10 случаях выявлена хроническая форма НЯК, при которой поверхность слизистой оболочки сглажена, атрофирована, с огромными рубцовыми полями и множеством полипов. Просвет кишки деформирован, стенка утолщена (рис. 3А). 


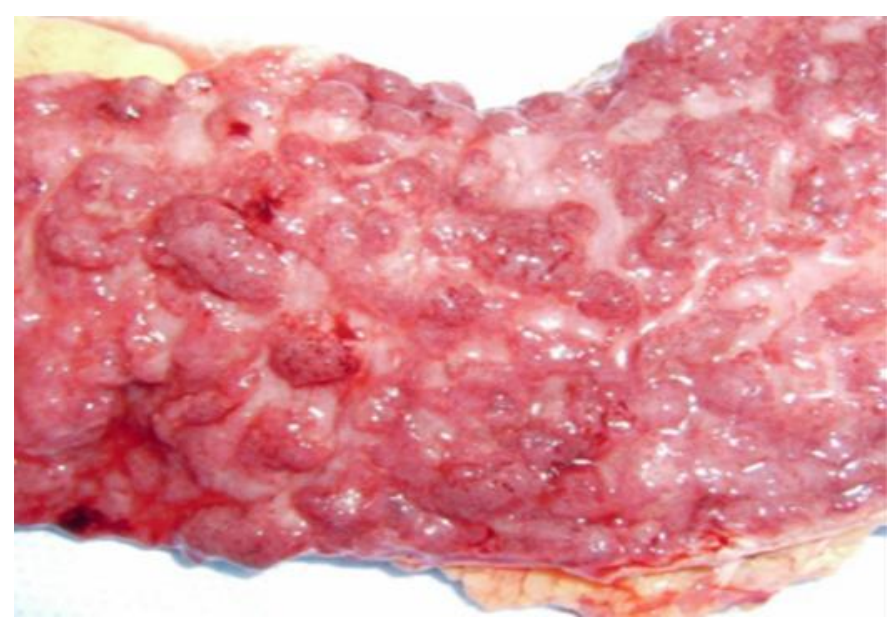

Рис. 3А. Операционный материал. Хронический неспецифический язвенный колит. Атрофированная слизистая оболочка сигмовидной кишки с рубцовыми полями и многочисленными полипами.

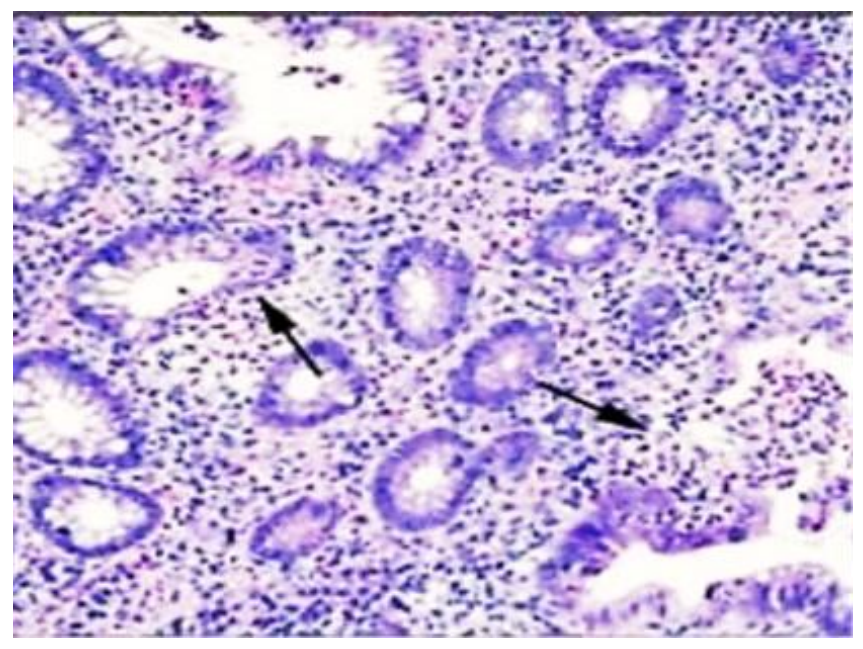

Рис. 3Б. Операционный материал. Хронический неспецифический язвенный колит. Атрофия слизистой оболочки, укорочение крипт, интенсивная лимфо-плазмоцитарная инфильтрация с крипт-абсцессами.

Метаплазией клеток Панета Окраска гематоксилином и эозином. Ув. X 200

При микроскопическом исследовании выявляется рубцевание язв и псевдополипов с деформацией просвета кишки, сохраняется лимфоцитарная и плазмоцитарная инфильтрация слизистой оболочки, что отражает продуктивный характер воспаления. Определяется полнокровие сосудов подслизистой оболочки. В сосудах выявляется продуктивный эндоваскулит, склероз стенок, запустевание просвета. Формируются крипт-абсцессы, укорочение кишечных крипт метаплазия клеток Панета (рис. 3Б). 
Обсуждение. В патогенезе неспецифического язвенного колита играет роль нарушение барьерной функции слизистой оболочки толстой кишки и регенераторных процессов. В основе повреждения лежит развитие аутоиммунного процесса, который характеризуется стимуляцией Т- и В-лимфоцитов с активацией иммуноглобулинов классов $\mathrm{M}$ и $\mathrm{G}$, комплексов антиген+антитело и активацией системы комплемента. В очаг воспаления устремляются такие клетки, как нейтрофилы и фагоциты, одновременно высвобождается большое количество медиаторов воспаления. За счет повреждения интрамурального нервного сплетения развиваются трофические нарушения, что способствует хронизации заболевания.

Из-за схожих клинических проявлений неспецифического язвенного колита нужно проводить дифференциальную диагностику с другими воспалительными заболеваниями кишечника, в первую очередь с болезнью Крона. Особенностью морфологических изменений в биоптатах при микроскопическом исследовании является выраженность гранулематозного воспаления во всех слоях кишки [4, с. 181], эпителиоидные гранулемы выявляются преимущественно в лимфоузлах и коже анальной области без очагов казеозного некроза, имеются гигантские клетки (рис. 4).

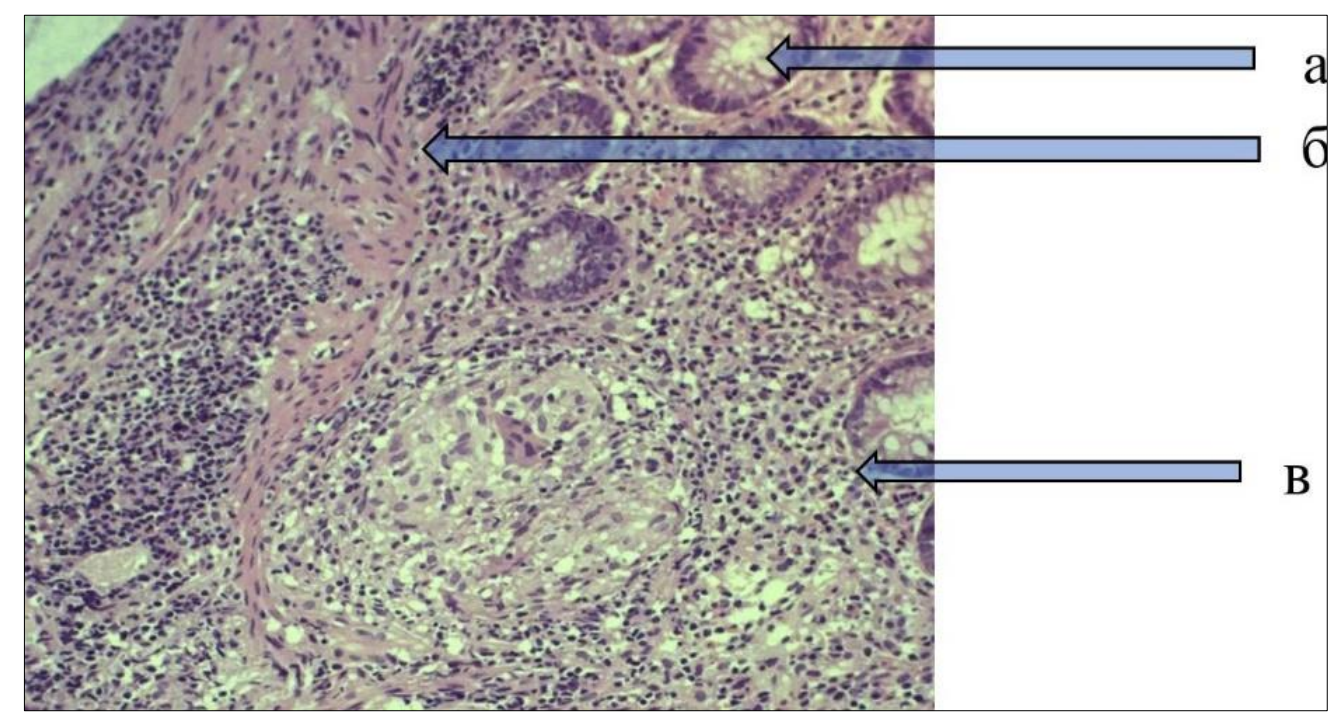

Рис. 4. Болезнь Крона. В стенке толстой кишки глубокая инфильтрация слизистой (а) и мышечной (б) оболочек, отмечается хроническое гранулематозное воспаление с многоядерными гигантскими клетками (в). Окраска гематоксилином и эозином. Ув. X 100

При исследовании биоптатов пациентов с инфекционным колитом отмечается наличие небольших атрофических крипт, гиалинизированная 
собственная пластинка слизистой оболочки, фибриновые тромбы (что характерно для формы, вызванной Escherichia coli). Для инфекции, вызванной Mycobacterium tuberculosis, характерны гранулемы с казеозным некрозом в центре, многоядерные гигантские клетки Пирогова - Лангханса.

Микроскопическая картина при амебном колите характеризуется присутствием амебных трофозоитов, деформацией крипт и изъязвлением слизистой оболочки (рис. 5). Язвы окружены узким валиком гиперемии и отека.

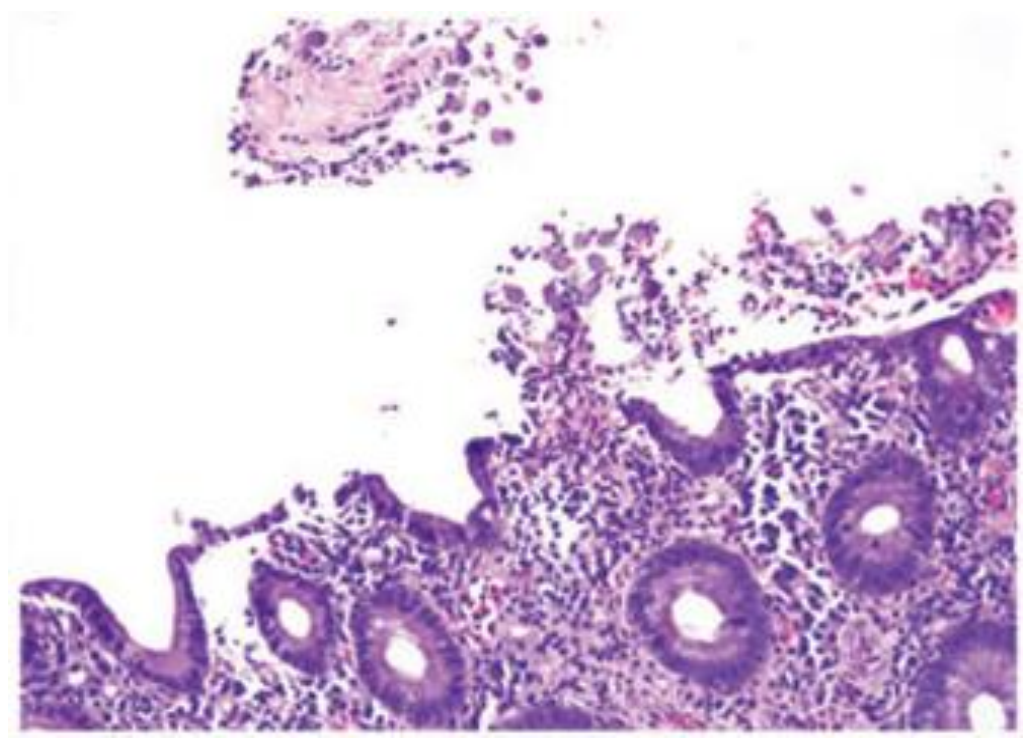

Рис. 5. Микроскопическая картина амебного колита. Проявление эпителиальной травмы: изъязвления слизистой, деформация крипт. Окраска гематоксилином и эозином. Ув.X200

Выводы. Биопсия слизистой оболочки является надежным, информативным методом для постановки диагноза неспецифического язвенного колита и дифференциальной диагностики его с другими заболеваниями кишечника, в первую очередь с болезнью Крона. Морфологическими особенностями при язвенном колите являются: искажение архитектоники крипт, наличие крипт-абсцессов и воспалительных клеток в слизистой оболочке (лимфоциты, плазматические клетки, а также гранулоциты). При болезни Крона характерно развитие неспецифического гранулематозного воспаления, охватывающего все слои кишечной стенки (трансмурального), в отличие от неспецифического язвенного колита, при котором воспаление ограничивается слизистой оболочкой. 


\section{Список литературы}

1. Baumgart DC, Sandborn WJ. Inflammatory bowel disease: clinical aspects and established and evolving therapies // Lancet. - May 12, 2007. - №369. C. 1641-1657.

2. Du L, Ha C. Epidemiology and Pathogenesis of Ulcerative Colitis. // Gastroenterol Clin North Am.- Dec 2020 - №49(4). - C. 643-654.

3. Нерсесян К.С. Операции по восстановлению резервуарной функции прямой кишки при специфических заболеваниях/ К.С. Нерсесян, Т. Акубардия, В.О. Арефина// Материалы Всероссийского научного форума с международным участием «Неделя молодежной науки - 2021». - 2021.- №1. C. 220.

4. De Roche TC. Histological evaluation in ulcerative colitis/ T.C. DeRoche, S.Y. Xiao, X. Liu // Gastroenterology Report 2. - 2014. - №3. - C. 178-92. 